KLEINE TEXTE FUR VORLESUNGEN UND UBUNGEN BEGRUNDET VON HANS LIETZMANN HERAUSGEGEREN VON KURT ALAND

\title{
POETARUM ROMANORUM VETERUM RELIQUIAE
}

\author{
SELEGIT \\ ERNESTUS DIEHL
}

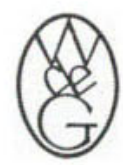

VERLAG WALTER DE GRUYTER \& CO. VORM. G. J. GOSCHEN'SCHE VERLAGSHANDLUNG - J. GUTTENTAG, VERLAGSBUCHHANDLUNG - GEORG REIMER - KARL J. TRUBNER - VEIT \& COMP. B E R LIN 1961 
Poetarum Romanorum veterum reliquias post Aemilium Baehrens edituro nova quodammodo fundamenta iecerunt $I$. Vahlen, Fr. Le o, Fr. Marx, viri huius aev: in litteris Latinis ingenii subtilitate et doctrina praeclarissimi, qui recensuerunt et enarraverunt carminum vetustissimonum atque Saturniorum versuum rudera, et Ennianae poesis reliquias ac C. Lucili carminum.

Gravissima illa linguae Latinae litterarumque Romanarum monumenta emendata ut iuventuti antiquitatis studiosae in manibus essent, quaecumque integram fere sententiam exhibebant e fragmentorum congerie excerpsi atque selegi adiecta praeter lectiones varias pressa ubi opus esse videbatur interpretatione.

Neque secludendas esse censui ab hac anthologia poetanum scenicorum reliquias Thesauri linguae Latinae in usum ab Ottone Ribbeck sub auspiciis divi Francisci Buecheler ante duodecim fere hos annos tertium editas, praesertim cum et recenti Nonii Marcelli editione a Wallacio Lindsay curata et Vahleni, Leonis, Skutschii aliorum studiis scenicis metricisque non uno tantum nomine tragicorum quoque et comicorum poetarum fragmenta pleraque emendatoria hodie legantur. Contra praeter Atellanarum mimorumque auctores celeberrimos poetas liberae rei publicae labentis bonos malosque in hoc concilium evocare nolui, ne praeter modum hoc volumen accresceret.

Auctorum veterum sigilla notasque criticas Thesauri $l$. L. indici in universum accommodavi et editorum usui pervulgato, reliqua autem revocant ad editorum recentium nomina, e quibus notaveris Leo $^{1}=$ Der Saturnische Vers v. Fr. Leo Berlin 1905, Leo ${ }^{2}=$ De Tragoedia Romana Observationes criticas scr. Fr. Leo Gott. 1910. 